
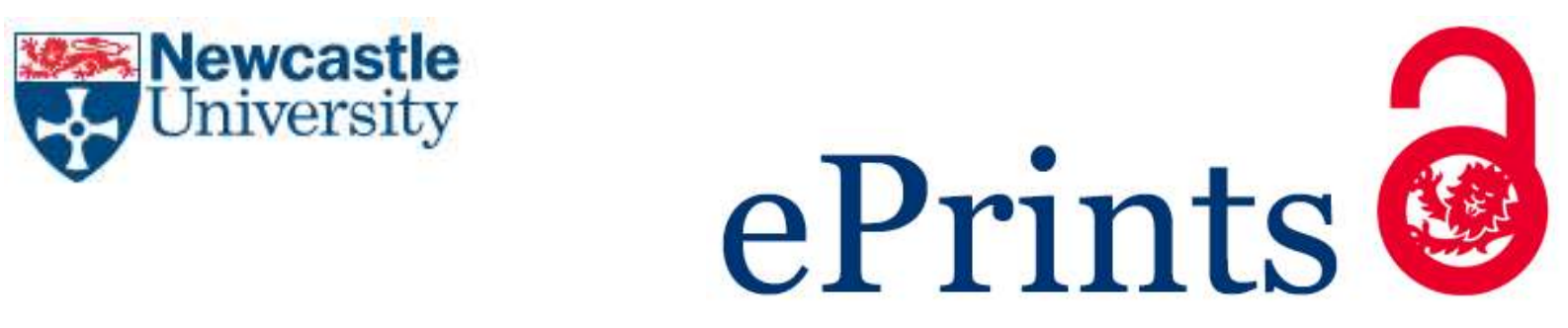

Gao G, Clare AS, Rose C, Caldwell GS. Intrinsic and extrinsic control of reproduction in the green tide-forming alga, Ulva rigida. Environmental and Experimental Botany 2017

\title{
Copyright:
}

(C) 2017. This manuscript version is made available under the CC-BY-NC-ND 4.0 license

DOI link to article:

http://dx.doi.org/10.1016/i.envexpbot.2017.03.016

Date deposited:

$03 / 04 / 2017$

Embargo release date:

28 March 2018

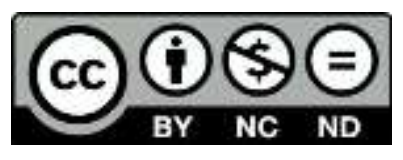

This work is licensed under a

Creative Commons Attribution-NonCommercial-NoDerivatives 4.0 International licence 


\section{Intrinsic and extrinsic control of reproduction in the green tide-forming alga, Ulva rigida}

Guang Gao, ${ }^{a, \#, *}$, Anthony S. Clare ${ }^{\mathrm{a}}$, Craig Rose ${ }^{\mathrm{b}}$, and Gary S. Caldwell ${ }^{\mathrm{a}, *}$

${ }^{a}$ School of Marine Science and Technology, Ridley Building, Newcastle University, Newcastle upon Tyne, NE1 7RU, England, UK

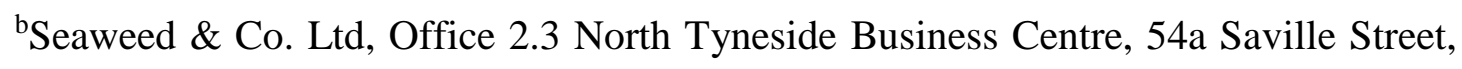
North Tyneside, NE30 1NT, England, UK

${ }^{\#}$ Current address: Marine Resources Development Institute of Jiangsu, Huaihai Institute of Technology, Lianyungang 222005, China

*Correspondence: Guang Gao, tel. $\quad+86 \quad(0) 518 \quad 8558$ 5003, e-mail: biogaoguang@126.com; Gary Caldwell, tel. +44 (0)191 208 6660, e-mail: gary.caldwell@ncl.ac.uk. 


\section{Abstract}

2 The green seaweed Ulva is the causative genus behind nuisance green tides, but also

3 has uses in the food and feed industries. Growing interest in Ulva cultivation has

4 highlighted knowledge gaps in the mechanisms that regulate maturation and

5 reproduction, particularly interacting intrinsic and extrinsic factors. In this study, the

6 effects of temperature shock, dehydration, culture temperature, nitrate concentration,

7 and thallus fragmentation were investigated on blade and basal tissue from $U$. rigida

8 thalli of varying ages. A 20-minute temperature shock induced a mean reproductive

9 response of $94.7 \%$ in blade tissue by day five. The reproductive rate of blade tissues

10 increased with the degree of fragmentation and with growth media renewal.

11 Combining temperature shock with fragmentation triggered $97.3 \%$ of blade tissues to

12 reproduce by day three. In contrast, dehydration reduced reproduction. A temperature

13 of $18^{\circ} \mathrm{C}$ in combination with a nitrate concentration of $100 \mu \mathrm{mol} \mathrm{L} \mathrm{L}^{-1}$ halved the

14 maturation period (28.4 days) compared to cultivation under lower temperature and

15 nitrate conditions (62.1 days). Reproduction in blade tissues increased with plant age

16 but basal tissues remained in the vegetative state even after temperature shock and

17 fragmentation. Furthermore, the presence of basal tissues suppressed reproduction of

18 blade tissues. These findings indicate that extrinsic factors such as temperature shock

19 and fragmentation induce reproduction in blade but not basal tissues, which appears to

20 be under the control of intrinsic factors such as sporulation inhibitors. The 
21 differentiation of Ulva cells could support the rapid growth of Ulva when

22 environmental conditions are favourable and also facilitate survival under

23 unfavourable conditions.

24 Keywords: dehydration; differentiation; fragmentation; reproduction; temperature;

25 Ulva

\section{1. Introduction}

Ulva is a cosmopolitan genus of green seaweed that can be found from tropical to polar climates and from fresh to fully saline environments (Rautenberger and Bischof, 2006; Shimada et al., 2008; Kirkendale et al., 2013). Robust capacities for nutrient uptake and growth have contributed to certain Ulva species becoming the problematic

31 agents behind worldwide green tide events (Smetacek and Zingone, 2013). On the

32 other hand, Ulva species are important in the food and feed industries and are gaining

33 increasing recognition as potential biofuel feedstock and as nutrient scrubbers for 34 bioremediation applications (Bikker et al., 2016). Ulva cultivation is widely practiced 35 (Lehahn et al., 2016), yet there remain gaps in our knowledge on key facets of Ulva's 36 biology, including its reproductive biology. Reproduction not only directly affects 37 productivity but can also be used to supply gametes for seedlings and should 38 eventually lead to full domestication. Ulva species tend to have complicated life cycles, generally involving an 40 alternation of isomorphic diploid sporophyte and haploid gametophyte phases. In 
41 addition, parthenogenetic development of gametes has also been found (Kapraun, 1970). In all cases, reproductive cells are directly transformed from vegetative cells (Hiraoka and Enomoto, 1998). The transition is initiated by extrinsic factors, with environmental temperature known to be important. For example, U. lactuca from Groton, USA, only reproduce in warmer months (Niesenbaum, 1988), whereas North Sea populations of $U$. pseudocurvata have approximate weekly reproductive peaks during the summer and biweekly peaks during colder seasons (Lüning et al., 2008). Kalita and Titlyanov (2011) shed further light on temperature regulation of reproductive rhythmicity by showing that the reproductive period of $U$. fenestrata decreased from 30 to five days when temperature increased from 10 to $20^{\circ} \mathrm{C}$, and ceased at $5^{\circ} \mathrm{C}$. Furthermore, rapid temperature changes have been found to induce gamete release over periods of hours to days (Niesenbaum, 1988; Carl et al., 2014a).

The effect of dehydration on gamete release is less clear. For example, Smith (1947) and Corradi et al. (2006) found that most Ulva blades discharged gametes five to 10 minutes after a dehydration period of one hour or less when followed by rehydration, whereas Carl et al. (2014a) found dehydration to be ineffective to increase sporulation. Tissue fragmentation is considered a powerful factor inducing reproduction (Nordby and Hoxmark, 1972; Nordby, 1977; Hiraoka and Enomoto, 1998; Dan et al., 2002; Gao et al., 2010). Fragmentation dramatically improved the sporulation rate of 

reported that reproduction of $U$. pertusa was induced two to three days after

63 fragmentation, with the reproductive rate increasing when fragment diameter

64 decreased from 10 to $0.9 \mathrm{~mm}$. Gao et al. (2010) demonstrated that $U$. prolifera

65 fragments of $0.5 \mathrm{~mm}$ diameter were almost entirely converted to sporangia whereas in

66 larger diameter fragments the sporangia only formed from the marginal and 67 submarginal cells. Nutrient availability also plays a role in reproduction of Ulva species. Mohsen et al. (1974) showed that nitrogen enrichment induced rapid sporogenesis and

70 sporulation, whereas depleted nitrogen led to zygospore formation in U. fasciata. In 71 addition, nitrate enrichment could significantly promote reproduction in $U$. rigida 72 over a 12-day cultivation (Gao et al., 2017). Intrinsic regulatory factors also contribute to reproductive regulation. Föyn 74 (1959) and Thiadens and Zeuthen (1966) reported that growth medium renewal 75 induced $U$. mutabilis to reproduce, inferring that substances in the fresh medium 76 induced sporulation rather than suppressing factors in the spent medium. However, 77 Nilsen and Nordby (1975) demonstrated that U. mutabilis reproduction was blocked 78 by high molecular weight carbohydrates extracted from living thallus fragments. 79 Further, Stratmann et al. (1996) identified two regulatory factors that maintain $U$. 80 mutabilis in the vegetative state: a glycoprotein termed sporulation inhibitor-1 (SI-1) 
81 and a non-proteinaceous compound termed sporulation inhibitor-2 (SI-2). SI-1 is a

82 cell wall component, the excretion of which decreases with thallus maturation, while

83 SI-2 occurs in the space between the two blade cell layers. The overall concentration

84 of SI-2 in the thallus remains constant throughout the life cycle. Each sporulation

85 inhibitor can inhibit gametogenesis. Furthermore, gamete release after gametogenesis

86 in species of Ulva could be controlled by a third substance, termed swarming inhibitor

87 (Wichard and Oertel, 2010; Vesty et al., 2015).

Although the Ulva thallus is organized simply with little functional

89 differentiation within the thallus, it does consist of at least two cell types: rhizoidal

90 cells in the basal parts and blade cells in the marginal parts of the thallus. Different

91 degrees of reproduction have been demonstrated between these thallus regions. More

92 than $90 \%$ of excised discs from the upper parts of the thallus in $U$. pertusa sporulated

93 while almost all discs from the basal parts did not mature three days after excision

94 (Hiraoka and Enomoto, 1998). A similar trend was found in U. pseudocurvata, in

95 which the degree of fertility increased from the basal to apical part of the thallus

96 (Lüning et al., 2008). Different reproductive performances across the Ulva thallus

97 might be due to the uneven distribution of sporulation inhibitors within the thallus,

98 with the highest concentration near the holdfast (Stratmann et al., 1996).

99 The studies aforementioned used mature Ulva plants, so little is known about 100 the effects of intrinsic and extrinsic factors on reproduction of the blade and basal 
101 parts of Ulva at varying ages. Accordingly, the precise role and interplay of intrinsic

102 and extrinsic factors remains unclear, particularly in relation to plant age. The

103 responses of Ulva at varying ages to environmental factors could be differential. In

104 our previous study, young $U$. rigida (less than 60 days post germination) did not show

105 any reproduction events during 60 days of culture, while the adult plants (more than

10660 days post germination) grown at higher temperature and nutrient replete conditions

107 (nitrate) had a reproduction rate of $64 \pm 5 \%$ by day 12 (Gao et al., 2017). Therefore,

108 young Ulva is deemed to be favourable for commericial cultivation compared to adult

109 Ulva as it could avoid periodic reproduction and thus growth fluctuation (Hiraoka and

110 Oka, 2008). Based on the previous studies, we hypothesised that the interplay of

111 intrinsic and extrinsic factors on reproduction of blade and basal tissues in $U$. rigida

112 would differ with plant age. We therefore investigated the role of temperature shock,

113 fragmentation and (assumed) sporulation inhibitors in controlling reproduction in

114 blade and basal tissues of $U$. rigida of different ages. This research provides important

115 insights into the regulation of reproduction in a commercially and ecologically

116 important green alga.

\section{2. Materials and methods}

\subsection{Seaweed collection}

119 Vegetative $U$. rigida plants of $12-15 \mathrm{~cm}$ in length were collected from the low

120 intertidal reaches of Cullercoats Bay, UK $\left(55.03^{\circ} \mathrm{N}, 1.43^{\circ} \mathrm{W}\right)$. Reproduction and 
121 swarmer release from temperate Ulva species usually occur during spring tides

122 (Lüning et al., 2008); therefore, plants were collected two days after a spring tide to

123 ensure that the plants were at an early stage of a lunar reproduction cycle and thereby

124 minimizing any effect of spring tides. The fronds were placed in a plastic bag and

125 transported to the laboratory within one hour and gently rinsed in $1 \mu \mathrm{m}$ filtered

126 seawater to remove any sediment, epiphytes or small grazers. The Ulva species used

127 in this study was identified by DNA barcoding at the Institute of Oceanology, Chinese

128 Academy of Sciences. It was found that the sequence, excluding the primers at both

129 ends, fully matched (100\%) to U. rigida SSBO0102 isolated from Skara Brae, Orkney,

130 Scotland (Gao, 2016). The plants were identified as gametophytes by microscopically

131 observing the released swarmers that had two flagella and exhibited positive

132 phototaxis.

\subsection{Culture conditions and determination of reproduction}

134 Ulva discs were excised from the vegetative thalli using a stainless steel punch

135 and rinsed with autoclaved seawater. After various treatments stated in the following

136 subsections, Ulva discs were cultured in 500-mL conical flasks filled with $300 \mathrm{~mL}$

137 autoclaved seawater at $18^{\circ} \mathrm{C}$ with a 16: 8 (L: D) photoperiod and light intensity of 80

$138 \mu \mathrm{mol}$ photons $\mathrm{m}^{-2} \mathrm{~s}^{-1}$. The flasks were aerated with a flow rate of $100 \mathrm{~L} \mathrm{~min}^{-1}$. The

139 nitrate and phosphate concentrations in the seawater were 100 and $5 \mu \mathrm{mol} \mathrm{\textrm {L } ^ { - 1 }}$ 
respectively, and the media was renewed daily. The temperature and photoperiod

141 were chosen as they are the ambient conditions at the sampling site during summer.

142 Reproductive Ulva discs were recognized by a colour change and was verified by

143 microscopy (Fig. 1). Vegetative cells were green in colour, containing several

144 granular chloroplasts (Fig. 1A). Thalli became pale green when becoming fertile due

145 to a change in the chloroplast position (Fig. 1B). Approximately 24 hours later,

146 pyriform gametes were formed within the sporangia (Fig. 1C) causing the thalli to

147 develop a yellowish appearance; gametes were subsequently liberated from the

148 sporangia (Fig. 1D). The cells become empty after discharging all gametes (Fig. 1C).

149 Sporulation in more than half of the disc area was considered as equivalent to

150 complete sporulation; the samples were checked daily. The reproduction rate was

151 recorded from the day when reproduction occurred to the end of the experiments

152 when the Ulva tissue samples yielded a reproductive success of over $90 \%$. Different

153 time periods were used in the following experiments as the effectiveness of different

154 induction methods varied. Triplicates were used in all experiments. The number of

155 discs used per replicate is stated within each experimental section.

\section{2.2.1. Temperature shock I}

157 Excised discs, with a diameter of $20 \mathrm{~mm}$, were placed in $500 \mathrm{~mL}$ flasks

158 containing $300 \mathrm{~mL}$ seawater at $4^{\circ} \mathrm{C}$ for $0,10,20,30,60,120,180$, or 360 minutes,

159 within a refrigerator. These flasks were then transferred to an $18^{\circ} \mathrm{C}$ incubator and the 
160 temperature of seawater in the flasks rose to $18^{\circ} \mathrm{C}$ within two hours. The flasks were

161 cultured as described above (see 2.2) for five days. The lower temperature and time

162 treatments were based on Carl et al. (2014a). The reproduction rates on days three,

163 four and five were recorded. Reproductive rate was determined as the ratio of

164 reproductive discs to all discs within a treatment.

165 2.2.2. Temperature shock II

166 To further understand the role of temperature shock, additional discs were treated

167 in five conditions. One group was kept at $18^{\circ} \mathrm{C}$ for two weeks with no temperature

168 shock (Zero); another was transferred from 18 to $4^{\circ} \mathrm{C}$ for two hours and returned to

$16918^{\circ} \mathrm{C}$ and then cultured at $18^{\circ} \mathrm{C}$ for two weeks; the remaining three groups were

170 transferred from 18 to $4^{\circ} \mathrm{C}$ and then cultured at $4^{\circ} \mathrm{C}$ for one, two, and three weeks,

171 respectively. In both temperature shock experiments each group had 25 discs per

172 replicate flask.2.2.3. Dehydration

173 The effect of dehydration was investigated by air-drying blade discs with a

174 diameter of $20 \mathrm{~mm}$ at room temperature $\left(20^{\circ} \mathrm{C}\right)$ for $0,15,30,60,120$ and 180 minutes,

175 then rehydrating in seawater and culturing them at $18^{\circ} \mathrm{C}$ as described above for two

176 weeks. These dehydration periods were chosen according to the previous studies on

177 Ulva species (Smith, 1947; Corradi et al., 2006; Carl et al., 2014a). The reproduction

178 rates on days 10,12 , and 14 were recorded. Twenty five discs were placed in each 179 flask. 
The upper regions of thalli were punched into discs with diameters of $2.5,4,6,8$,

182 and $10 \mathrm{~mm}$. Disc sizes were based on Hiraoka and Enomoto (1998) and Gao et al.

183 (2010). To test the hypothesis that fragmentation can stimulate reproduction via

184 releasing sporulation inhibitors into the media (Hiraoka and Enomoto, 1998), half of

185 the discs were cultured in media without renewal while the other half was cultured in

186 media that was renewed daily for seven days under culture conditions as described in

187 section 2.2 . The consumed nitrate and phosphate were replenished daily for those

188 media without renewal to avoid any effect of nutrient limitation. The reproduction

189 rates on days five, six, and seven were recorded. The numbers of discs with diameters

190 of $2.5,4,6,8$, and $10 \mathrm{~mm}$ were $320,125,56,31$, and 20 , respectively, to guarantee

191 equal densities across treatments.

\subsubsection{Combination of temperature shock, dehydration, and fragmentation}

Discs (fragments: FR) with diameters of 2.5, 4, and $6 \mathrm{~mm}$ were punched from

194 the upper thalli regions (FR) and subjected to either one hour of dehydration (FR+DE),

195 six hours of temperature shock (FR+TS), or six hours of temperature shock plus one

196 hour of dehydration (FR+TS+DE). The disc size, temperature shock, and dehydration

197 times were selected due to their effects on reproductive induction in the experiments

198 in sections $2.3,2.4$, and 2.6. The number of discs with diameters of $2.5,4$, and $6 \mathrm{~mm}$ 
199 were 320,125 , and 56, respectively, to ensure equal densities across treatments. The 200 reproduction rates on days two, three, and four were recorded.

\subsubsection{Reproduction of blade and basal parts of Ulva thalli with age}

The effects of intrinsic and extrinsic factors throughout development were

203 investigated using $2.5 \mathrm{~mm}$ diameter discs excised from the blade and basal regions of

204 thalli of differing ages (20, 30, 40, 50, and 60 days). We define basal regions as those

205 within a $15 \mathrm{~mm}$ distance from basal end and blade regions as those within 105-150

206 mm distances from basal end (Hiraoka and Enomoto, 1998; Lüning et al., 2008).

207 Twenty five discs were placed in each of three flasks per treatment. Every flask

208 experienced six hours of temperature shock $\left(4^{\circ} \mathrm{C}\right)$ before being cultured for 14 days as

209 described above. The reproduction rates on days seven, 10, and 14 were recorded. The

210 period was selected as it was sufficient for reproduction of the blade parts based on

211 the experience of normal laboratory culture. Different ages of Ulva thalli were

212 obtained from the development of gametes. Discharged gametes were attracted to a

213 point-source light using a fibre optic illuminator, collected with a pipette, and

214 transferred to sterile seawater. Afterwards, $20 \mathrm{~mL}$ aliquots of gamete suspension with

215 a concentration of $1.0 \times 10^{5}$ gametes $\mathrm{mL}^{-1}$ were placed in Petri dishes and kept in

216 darkness for 24 hours to ensure even settlement. The culture conditions for settled

217 gametes were the same as for the disc cultures. 
Discs from blade (20 $\mathrm{mm}$ diameter discs) and basal (5 $\mathrm{mm}$ diameter discs) parts

220 of the thalli were used to study the potential mechanisms that basal cells use to

221 maintain vegetative status across the whole life history. Different sized discs were

222 used to easily distinguish between tissue types during reproduction examination. Four

223 ratios of blade to basal discs were set up in increments of 20 discs: (1: 0, i.e. 20 blade:

2240 basal discs), blade: basal (1: 1, i.e. 20: 20), blade: basal (1: 2, i.e. 20: 40) and blade:

225 basal (1: 3 , i.e. 20 : 60$)$. These ratios were based on a preliminary experiment showing

226 that a ratio of 1: 3 could completely inhibit reproduction in blade discs. The

227 experiment was conducted for 15 days and in triplicate. The reproduction rates on

228 days 13,14 , and 15 were recorded.

\subsection{Effects of temperature and nitrate on maturation of $\mathrm{U}$. rigida}

The gametes used in this experiment were collected and settled as described in

231 section 2.2.6. To investigate the effects of extrinsic factors on maturation, settled

232 gametes were cultured at two fully crossed temperature $\left(14,18^{\circ} \mathrm{C}\right)$ and nitrate $(6,100$

$\left.233 \mu \mathrm{mol} \mathrm{L}{ }^{-1}\right)$ conditions, giving four treatments: 1$)$ low temperature $\left(14^{\circ} \mathrm{C}\right)$ and nitrate $(6$

$234 \mu \mathrm{M} \mathrm{N}), 2)$ low temperature $\left(14^{\circ} \mathrm{C}\right)$ and high nitrate $\left.(100 \mu \mathrm{M} \mathrm{N}), 3\right)$ high temperature

$235\left(18^{\circ} \mathrm{C}\right)$ and low nitrate $(6 \mu \mathrm{M} \mathrm{N})$, and 4$)$ high temperature $\left(18^{\circ} \mathrm{C}\right)$ and nitrate $(100 \mu \mathrm{M}$

$236 \mathrm{~N})$. The phosphate concentration in the seawater was set at $5 \mu \mathrm{mol} \mathrm{L} \mathrm{L}^{-1}$ for all

237 treatments. The lower temperature and nitrate levels reflected those at the sampling 
238 site (Gao et al., 2017). The higher temperature is the projected value by the end of this

239 century and the higher nitrate level is indicative of coastal eutrophication (Gao et al.,

240 2017). Germlings were cultured as described above and manually detached when they

241 reached $1 \mathrm{~mm}$ in length, and ten individuals from each treatment were randomly

242 selected for further culture. Each individual was grown in a $500 \mathrm{~mL}$ conical flask. The

243 culture conditions were the same as aforementioned. Germling length was measured

244 every three or four days and the time taken to reach $1.5 \mathrm{~cm}$ was recorded (see

245 supplementary Fig. S1).

\section{2.4. Statistical analysis}

Results were expressed as means of replicates \pm standard deviation. Statistical

248 analysis was carried out with SPSS v21. The data from every treatment conformed to

249 a normal distribution (Shapiro-Wilk, $P>0.05$ ) and had equal variances (Levene's test,

$250 P>0.05)$. A repeated measures ANOVA (RM-ANOVA) was conducted to assess the

251 effect of culture time on reproduction in each experiment. One-way multivariate

252 ANOVAs (MANOVAs) were used to analyse the effects of temperature shock,

253 dehydration, age, or basal cells on reproduction of blade cells on different days. A

254 two-way MANOVA was conducted to assess the effects of fragmentation and media

255 on blade cell reproduction on different days. A three-way MANOVA was conducted

256 to assess the effects of temperature shock, dehydration, and fragmentation on different

257 days. A two-way ANOVA was conducted to assess the effects of temperature and 

conducted for post hoc investigation. A confidence interval of $95 \%$ was set for all 260 tests.

\section{3. Results}

\subsection{Temperature shock}

There was a significant interaction between culture time and temperature shock time (RM-ANOVA, $\left.F_{(14,32)}=104.530, P<0.001\right)$. Ulva discs without temperature shock did not show any reproduction during five days of culture while those experiencing temperature shock became reproductive within five days (Fig. 2). There

267 were statistically significant differences in reproduction rates between temperature 268 shock times on days three, four, and five (MANOVA, $F_{(7,16)}>133.029, P<0.001$; 269 Fig. 2). On day three, a 20-minute temperature shock was insufficient to trigger 270 reproduction, while a 30 -minute shock caused a reproduction rate of $24.0 \pm 4.0 \%$, 271 increasing to $36.0 \pm 4.0 \%$ with a 60 -minute shock (Tukey HSD, $P<0.05$ ). Further 272 increases to shock duration were ineffective until 360 minutes whereupon 273 reproduction increased to $48.0 \pm 4.0 \%$. Reproduction rates on day four follow a 274 similar trend as on day three - a slight increase for extended shock periods with the 275 highest rate at the longest temperature shock time. By day five, a 10-minute shock 276 triggered $36.0 \pm 4.0 \%$, increasing to $94.7 \pm 2.3 \%$ after a 20 -minute shock. Further 277 shock period extensions had no significant impact. It is interesting to note that Ulva 
278 discs did not sporulate if they experienced a low temperature of $4{ }^{\circ} \mathrm{C}$ for one, two, or 279 three weeks without returning to the high temperature of $18^{\circ} \mathrm{C}$ (Fig. 3).

280

\subsection{Dehydration}

There was a significant interaction between time of culture and dehydration $\left(\right.$ RM-ANOVA, $\left.F_{(10,24)}=28.887, P<0.001\right)$. In general, reproduction rate increased over time and decreased with increasing dehydration times (Fig. 4). This trend was consistent over time, and dehydration significantly reduced reproduction compared to the control (ANOVA, $F_{(5,12)}>140.800, P<0.001$ ). Notably, there was no reproduction in discs dehydrated for 180 minutes within 14 days of culture.

\subsection{Fragmentation and media}

There was a significant interaction between culture time and fragmentation $\left(\mathrm{RM}-\mathrm{ANOVA}, F_{(8,40)}=19.058, P<0.001\right)$ or media $(\mathrm{RM}-\mathrm{ANOVA}, \mathrm{F}=7.777, \mathrm{df}=2$, $40, P=0.001$ ), which suggests that the changes of reproduction rates with time were different between fragmentation or media treatments. On day five, fragmentation and media interacted significantly (MANOVA, $F_{(4,20)}=74.902, P<0.001$; Fig. 5). The influence of the media treatments was reduced as disc size increased (Fig. 5). For instance, the reproduction of $2.5 \mathrm{~mm}$ discs was $75.5 \pm 2.4 \%$ in renewed media and $39.1 \pm 1.6 \%$ in non-renewed media, whereas for $4 \mathrm{~mm}$ discs it was $24.3 \pm 2 \%$ and $18.1 \pm 2 \%$ in renewed and non-renewed media, respectively. This trend was similar on day six and seven (Fig. 5). The mean reproduction rate of discs grown in renewed 

media $(56.2 \pm 26.0 \%)$ was higher than that in non-renewed media $(39.0 \pm 22.1 \%)$ on day seven and this trend was consistent from five days onwards. The reproduction rate decreased with increasing disc size with a minimum of $5.0 \pm 5.0 \%$ (non-renewed media) and $20.0 \pm 5.0 \%$ (renewed media) for $10 \mathrm{~mm}$ discs and a maximum of $64.7 \pm$ $2.7 \%$ (non-renewed media) and $92.2 \pm 5.6 \%$ (renewed media) for $2.5 \mathrm{~mm}$ discs on day seven.

\subsection{Combination of temperature shock, dehydration, and fragmentation}

The combined effects of temperature shock, dehydration, and fragmentation on reproduction, over four days of culture were investigated (Fig. 6). Culture time had an interactive effect with fragmentation (RM-ANOVA, $F=3.725$, $\mathrm{df}=4,48, P=0.010$ ) and temperature shock (RM-ANOVA, $F=403.774$, $\mathrm{df}=2,48, P<0.001$ ). The maximum reproduction rate of small discs was reached after three days while medium and large discs reached a maximum on day four (Fig. 6). Discs without temperature shock did not show any reproduction during five days of culture while those with temperature shock demonstrated an increased reproduction rate with time (Fig. 6). On day two, temperature shock interacted with fragmentation (MANOVA, $F_{(2,24)}=$ 94.920, $P<0.001$ ) and dehydration (MANOVA, $F_{(1,24)}=146.463, P<0.001$ ) (Fig. 6A). The reproduction rates of three sizes of discs with temperature shock (FR+TS) were $64.0 \pm 3.9 \%$ (small discs), $48.0 \pm 4.0 \%$ (medium discs), and $34.5 \pm 2.1 \%$ (large discs) respectively, with none reproducing without a temperature shock (FR). 
318 Similarly, discs experiencing dehydration $(\mathrm{FR}+\mathrm{DE})$ did not reproduce, while $44.0 \pm$

$3193.9 \%$ (small discs), $24.0 \pm 4.0 \%$ (medium discs), and $6.5 \pm 6.3 \%$ (large discs),

320 respectively, were reproductive when temperature shocked (FR+DE+TS). On day

321 three (Fig. 6B), any combination of two of the three factors interacted to promote

322 reproduction (MANOVA, $F>7.958, P<0.01$ ). Discs of all sizes did not reproduce

323 without a temperature shock. Small discs demonstrated the biggest decline in

324 reproduction rate when dehydration was added. The highest reproduction $(97.3 \pm$

$3252.4 \%$ ) was in the smallest discs in combination with temperature shock. The pattern

326 on day four (Fig. 6C) was similar to day three. On all three days, fragmentation

327 significantly affected reproduction (MANOVA, $F_{(2,24)}>65.976, P<0.001$ ) as

328 reproduction decreased with increasing disc size.

\subsection{Reproduction of blade and basal $\mathrm{U}$. rigida tissues with age}

There was a significant interaction between culture time and disc age

331 (RM-ANOVA, $F_{(8,20)}=10.162, P<0.001$ ), suggesting the changes of reproduction of

332 blade discs at different ages with culture time were not the same. For example, the

333 reproduction rates of 20 -day-old discs were $1.3 \pm 2.3 \%$ on day seven, $1.3 \pm 2.3 \%$ on

334 day $10,2.7 \pm 2.3 \%$ on day 14 , while they were $50.7 \pm 4.6 \%$ on day $7,84.0 \pm 4.0 \%$ on

335 day 10 and $92.0 \pm 4.0 \%$ on day 14 for 40-day-old discs (Fig. 7). There were

336 statistically significant differences in reproduction rates of blade discs of differing

337 ages on days seven, 10 , and 14 (ANOVA, $F_{(4,10)}>115.578, P<0.001$; Fig. 7). On 
day seven (Fig. 7A), 20-day-old discs showed little reproduction, with reproduction rate increasing with age (from 30 to 60 days), reaching $84.0 \pm 4.0 \%$ in 60 -day-old discs. On day 10 (Fig. 7B), the reproduction rate increased by more than five times when disc age changed from 20 to 40 days (Tukey HSD, $P<0.05$ ). The difference in reproduction between 40- and 50-day-old or 50- and 60-day-old discs was not statistically significant. Sixty-day-old discs, however, had a higher reproduction rate $(97.3 \pm 2.3 \%)$ than 40 -day-old discs. The pattern on day 14 (Fig. 7C) was the same as day 10. No reproduction was found in basal discs regardless of age or culture time (Fig. 7).

\subsection{Inhibitory effects of basal cells}

There was a significant interaction between the ratios of blade to basal discs and culture time (RM-ANOVA, $\left.F_{(6,16)}=10.162, P=0.001\right)$, suggesting that the changes of reproduction with varying ratios of blade to basal discs with time were different. For example, reproduction rates of blade discs with 60 basal discs $(1: 3)$ were $0.0 \pm 0$. $0 \%$ (day 13), $3.3 \pm 2.9 \%$ (day 14 ), and $8.3 \pm 2.9 \%$ (day 15 ) respectively; while they were respectively $25.0 \pm 5.0 \%$ (day 13 ), $53.3 \pm 5.8 \%$ (day 14 ), and $70.0 \pm 5.0 \%$ (day 15) for blade discs with 20 basal discs (1:1) (Fig. 8). There were significant differences in reproduction rates of blade discs with the addition of basal discs (MANOVA, $F_{(3,8)}>122.769, P<0.001$; Fig. 8). On day 13, blade discs alone $(1: 0)$ had $60.0 \pm 5.0 \%$ reproduction, which declined to $25.0 \pm 5.0 \%$ when 20 basal discs 
358 were added (1:1), and further to $8.3 \pm 2.9 \%$ with 40 basal discs (1:2) (Tukey HSD, $P$

$359<0.05)$. Blade discs mixed with 60 basal discs $(1: 3)$ did not become reproductive.

360 Similar pattern were detected on days 14 and 15 except that the treatment with 60

361 basal discs (1:3) did show some reproduction, albeit at very low levels $(3.3 \pm 2.9 \%$ on

362 day 14 and $8.3 \pm 2.9 \%$ on day 15$)$.

363 3.7. Effects of temperature and nitrate on maturity of $\mathrm{U}$. rigida

364 Temperature and nitrate had a significant interaction on maturity time of $U$.

365 rigida (ANOVA, $F_{(1,36)}=33.085, P<0.001$ ) and each of them had a main effect

$366 \quad\left(\right.$ ANOVA, $F_{(1,36)}=461.693, P<0.001$ for temperature; ANOVA, $F(1,36)=532.399$,

$367 P<0.001$ for nitrate). Maturation took $62.1 \pm 2.8$ days when plants were grown under

368 conditions of low temperature and low nitrate (Fig. 9). High temperature $\left(18^{\circ} \mathrm{C}\right.$ and 6

$369 \mu \mathrm{M} \mathrm{N})$ and high nitrate $\left(14^{\circ} \mathrm{C}\right.$ and $\left.100 \mu \mathrm{M} \mathrm{N}\right)$ shortened the time to $40.3 \pm 2.2$ and

$37041.5 \pm 2.5$ days respectively. The high temperature and high nitrate condition $\left(18^{\circ} \mathrm{C}\right.$

371 and $100 \mu \mathrm{M} \mathrm{N}$ ) promoted the shortest maturation period of $28.4 \pm 2.0$ days.

\section{4. Discussion}

The intrinsic and extrinsic factors regulating the reproductive biology of the

376 problematic green tide-forming green algae, Ulva rigida, were investigated in this 
377 study. The intention was to better inform the management of green tide events

378 through a more in-depth understanding of reproductive cues - an important

379 consideration given the predicted response of green tides to climate change (Gao et al.

380 2017) - and to support the development of hatchery systems for sustainable Ulva

381 cultivation.

\subsection{Effects of temperature shock}

Temperature shock is an established method to induce gamete release, but the

384 efficacy of the approach varies with species and ecotype. In the present study, a 385 minimum of a 10-minute temperature shock was necessary to trigger reproduction (36 $386 \pm 4 \%$ ) after culturing for five days (Fig. 2). Carl et al. (2014a), using the tropical Ulva 387 sp. 3 (subsequently named as U. tepida; Masakiyo and Shimada, 2014), reported 10 388 minutes to be the saturation time for reproductive induction, with extended shock 389 duration failing to enhance zooid formation. Our data, however, show that 20 minutes 390 is required for saturation in this temperate $U$. rigida strain. In terms of release period,

391 it took five days for discs experiencing 10-minute temperature shock to become 392 reproductive $(36.0 \pm 4.0 \%)$ in the current study, yet Carl et al. (2014a) achieved a 393 similar sporulaton rate after two days using the same temperature shock time. 394 Furthermore, Niesenbaum (1988) reported that $U$. lactuca thalli became reproductive 39518 hours after a $2^{\circ} \mathrm{C}$ wash. 
397 stimulation. However, Carl et al. (2014a) switched between four and $25^{\circ} \mathrm{C}$ compared 398 with four and $18^{\circ} \mathrm{C}$ in the present study; the $7^{\circ} \mathrm{C}$ difference equates to a more 399 definitive temperature shock that may also have contributed towards the saturation 400 time differences. Assuming that the degree of deviation from the environmental norm 401 is a telling factor in the effectiveness of temperature shock, then by extrapolation, 402 Ulva from more polar environments would be expected to experience even lower 403 reproductive rates as a drop to $4^{\circ} \mathrm{C}$ would equate to the weakest temperature shock 404 relative to its ecological norm. This, however, assumes equal sensitivity to 405 temperature across geographically- and ecologically-distant strains. As far as the 406 authors are aware, this latitudinal relationship between temperature shock and 407 reproduction in Ulva has not been investigated.

408 The shorter time required for fertility of Ulva species experiencing temperature 409 shock reported in previous studies (Niesenbaum, 1988; Carl et al., 2014a) could be 410 down to the pre-fertile status of the plants, as gamete discharge was also found in the 411 control group; temperature shock merely accelerated the release process. It is 412 suggested that a minimun of two days is required for the transition from vegetative to 413 reproductive status (Wichard and Oertel, 2010). The enhanced reproduction under 414 temperature shock may be a survival strategy under unfavourable conditions (Li and 415 Brawley, 2004). 
417 triggered another reproductive pathway remains to be determined. The process 418 appears to involve a two-step mechanism. The first step is from high temperature to 419 low temperature and the second is returning to a high temperature. Neither is 420 dispensable, as continuous low temperature induction for three weeks, without 421 returning to high temperature, did not trigger reproduction. This finding is supported 422 by previous studies wherein it was shown that $U$. fenestrata cannot form reproductive 423 cells at $5^{\circ} \mathrm{C}$ (Kalita and Tytilanov, 2011) and gamete release in $U$. mutabilis only 424 occurs within a narrow temperature range between 15 and $25^{\circ} \mathrm{C}$ (Wichard and Oetel 425 2010).

\subsection{Effects of dehydration}

Dehydration did not stimulate reproduction of $U$. rigida despite the use of longer dehydration times (up to 180 minutes) than previously reported (maximum 60 minutes). On the contrary, reproduction decreased as dehydration time extended. This

430 agrees with Carl et al. (2014a) but contrasts with Corradi et al. (2006) in which thalli 431 subjected to a 10- or 20-minute dehydration released gametes within three days. 432 Furthermore, Smith (1947) reported that Ulva blades dried for one hour liberated 433 gametes five to 10 minutes after reimmersion. Those thalli should be already 434 reproductive and dehydration merely stimulated gamete release as no transformation 435 from vegetative to reproductive status could happen within such a short time 
436 (Wichard and Oertel, 2010). Dehydration, unlike temperature shock, may not serve as

437 an effective environmental stimulus as Ulva growing intertidally will experience two

438 emersion periods per lunar day. Tidal emersion does not convey seasonal cues, unlike

439 temperature and photoperiod for instance.

\subsection{Effects of temperature and nitrate on maturation}

Extrinsic factors that are more stable and persistent than temperature shock can

442 also accelerate Ulva maturation and reproduction. Culturing at elevated temperature

443 and/ or nitrate conditions shortened the time to maturity in this study by over half.

444 Likewise, the reproductive rhythm of $U$. fenestrata decreased from 30 to five days

445 when temperature was increased from 10 to $20^{\circ} \mathrm{C}$ (Kalita and Titlyanov, 2011) and

446 higher temperature interacting with nitrate also induced more reproduction in $U$.

447 rigida (Gao et al., 2017). Moderate temperatures can accelerate growth and 448 reproduction by increasing enzyme activity, and increased nitrogen availability can 449 support an accelerated synthesis of nucleotides and proteins (Iken, 2012). For 450 example, up to $32 \%$ of genes in Saccharina latissima had altered expression profiles 451 in respose to changes of temperature and light, with the highest transcription rates at 452 the high temperature and light treatments (Heinrich et al., 2012). In terms of the time 453 to maturity, thalli of $U$. mutabilis became fertile at an age between 18 and $24( \pm 2)$ 454 days (Stratmann et al., 1996), which was earlier than the $U$. rigida (28 \pm 2 days) even 
under optimal conditions in this study. This can mainly be ascribed to species difference since the $U$. mutabilis used was a fast-growing mutant.

\subsection{Effects of fragmentation}

Ulva species grow along with Porphyra yezoensis by attaching to the net curtain and rafts used for Porphyra aquaculture in China. The thalli fragments of Ulva produced during cleaning of ropes, rafts and other attachments after $P$. yezoensis is harvested are deemed to be the sources of green tides in China (Liu et al., 2009). In addition, fragmentation of Ulva thalli commonly occurs in the sea due to the action of grazers, waves, and propellers, and is suggested as one of the main factors hastening the occurrence and spread of green tides by inducing vast sporulation events (Gao et al., 2010). For $U$. rigida, smaller tissue discs resulted in greater reproduction which is consistent with U. pertusa (Hiraoka and Enomoto, 1998) and U. prolifera (Gao et al., 2010). These findings indicate that an increase in reproduction with decreasing fragment size may commonly exist in Ulva species.

There are two hypotheses relating to fragmentation-induced reproduction. The first is that wounding triggers the expression of genes coding for sex-inducing pheromones, such as in the green alga Volvox (Amon et al., 1998). Smaller discs have a higher ratio of wounded cells to total cells, which would translate into a stronger reproductive stimulation. This hypothesis could now be tested in $U$. linza as a baseline set of transcripts is available (Zhang et al., 2012), but currently the molecular tools are 
unavailable for $U$. rigida. The second hypothesis is that Ulva blade cells produce two reproduction suppressors; one (SI-1) is excreted into cell walls and the other (SI-2) is located in the inner space between the two cell layers (Stratmann et al., 1996). Cutting breaks the cell wall and extracelluar matrix structure making it easier for small discs to leach inhibitors, thereby removing the regulatory block to reproduction (Hiraoka and Enomoto, 1998). This hypothesis was supported by differences in reproduction between Ulva grown in old and renewed media. More wounding sites could have resulted in greater release of inhibitors into the media which were removed following media exchange. Testing of this hypothesis would require a detailed metabolomics study, such as advocated by Simpson et al. (2011), Goulitquer et al. (2012) and Gupta et al. (2014). To our knowledge, such a focused metabolomics study has yet to be been done on Ulva in relation to growth and reproduction inhibitors.

\subsection{Combined effects of extrinsic and intrinsic factors}

As mentioned above, dehydration did not stimulate reproduction of $U$. rigida during 14-day culture, while temperature shock and fragmentation could induce reproduction occurrence by days three and five, respectively. This suggests that temperature shock has more power to induce reproduction in $U$. rigida compared to dehydration and fragmentation. Meanwhile, a combination of fragmentation and temperature shock shortened the time to zooid formation and discharge compared to each factor singularly. This indicates that the regulation of Ulva reproduction is a 
495 496 497 498 511 became reproductive after five days of nursery and 13 days of outdoor cultivation 512 (Carl et al., 2014b).

comprehensive and interactive process of intrinsic and extrinsic factors. Fragmentation would have freed the tissue from regulatory sporulation inhibition (Hiraoka and Enomoto, 1998), thus initiating the transition from vegetative to reproductive status, while temperature shock will have accelerated the process. This promoting effect was moderated somewhat by dehyration, providing futher evidence that dehydration is not a fertility stimulator (Carl et al., 2014a).

\subsection{Reproduction of blade and basal cells with age}

The reproduction rate of blade cells increased with age and indicates that blade cells of older Ulva are more sensitive to stimulatory triggers. This changing sensitivity might be due to differing regulatory factor excretion capabilities in blade cells with age. Stratmann et al. (1996) reported that the excretion of sporulation inhibitor SI-1 in blade cells decreased with maturation of $U$. mutabilis. That is why young Ulva seldom become reproductive whereas old Ulva are liable to release swarmers (Gao et al., 2017). When the amount of excreted sporulation inhibitor is not enough to control the induction of enviromental factors, reproduction occurs. The finding that reproduction is highly age-depedent has also been noted in $U$. tepida that

On the other hand, no reproduction occured in basal cells from either young or mature thalli that experienced temperature shock and fragment, which suggests the 
515 basal cells can maintain vegetative status over the whole life span. This could be due

516 to their lifetime excretion of sporulation inhibitors. The sporulation inhibitor produced

517 by basal cells can be released into the medium (Stratmann et al., 1996), and was

518 observed to proportionately inhibit reproduction in blade discs. Furthermore, the

519 excretion of sporulation inhibitors in basal cells was not affected by environmental

520 stresses, such as temperature shock and fragmentation. The robust excretion of

521 sporulation inhibitors from basal cells - thus inhibiting the reproduction of blade cells

522 - may potentially explain the phenomenon that swarmer release of Ulva species

523 usually happens during spring tides (Smith, 1947; Lüning et al., 2008). Consider Ulva

524 species living in closed ditches or tide pools, or within the upper intertidal zone; the

525 reproduction of blade cells is inhibited by basal cell sporulation inhibitors . Seawater

526 can reach the highest level of the intertidal zone and may dilute the sporulation

527 inhibitors during spring tides. Consequently, swarmers are induced and released

528 without the direct control of sporulation inhibitors (Smith, 1947; Stratmann et al.,

529 1996; Lüning et al., 2008). It is worth noting that the dilution effect should not be the

530 only link between swarmer release and spring tides. The moonlight could also

531 contribute to the periodic reproduction of Ulva species in the field (Lüning et al.,

532 2008). The synchronous swarming would result in a considerable enhancement of

533 mating success and support the optimal distribution of swarmers and offspring within

534 the habitat (Stratmann et al., 1996). 
536 blade cells (decreasing excretion) with age may have led to the functional 537 differentiation between the cell types. This differentiation could benefit Ulva's 538 response to environment signals. Blade cells are more sensitive to environmental 539 change. High productivity and quick growth of the blade allows Ulva to rapidly 540 invade primary substrata as an opportunistic species when conditions are favourble.

541 Meanwhile, under unfavourable conditions the blade can quickly transform from 542 vegetative to reproductive states, discharge swarmers and finally die off, while basal 543 tissue persists from which new thalli arise during each subsequent growing season.

\section{5. Conclusions}

545 The interactions of extrinsic and intrinsic factors regulating the reproduction of 546 differently aged $U$. rigida thalli were investigated for the first time. Blade tissues of 547 mature thalli responded strongly to both temperature shock and fragmentation 548 whereas dehydration countered maturation and gamete release. The combination of 549 temperature shock and fragmentation was the most powerful tool to induce 550 reproduction in blade tissues. The response of blade tissues increased with age 551 whereas basal tissues remained non-reproductive. Basal tissues suppressed the 552 reproductive response of blade tissues when they were co-cultured, indicating that 553 intrinsic signalling factors, such as sporulation inhibitors, dominate reproductive 554 regulation. The differentiation of Ulva cells with time leads to contrasting 
555 reproductive performance in both regions of the plant, which not only supports the

556 rapid growth of Ulva when environmental conditions are favourable but also aids

557 survival during unfavourable conditions. These findings provide important

558 information that furthers our understanding of the ecological success of Ulva,

559 particularly in green tide situations. This will become increasingly important as

560 climate change and human land use practices continue to create conditions favourable

561 for green tide formation. In addition, the findings in the present study also make a

562 useful contribution to the development of hatchery systems for sustainable Ulva

563 cultivation.

\section{Acknowledgements}

565 This research was funded by a School of Marine Science and Technology

566 doctoral scholarship awarded to GG, the Science Foundation of Huaihai Institute of

567 Technology (Z2016007), and the Open Project Program of Marine Resources

568 Development Institute of Jiangsu (JSIMR201601). We thank David Whitaker for his

569 assistance over the duration of this project. CR is Director of Seaweed \& Co. Ltd

570 which advises on the supply and quality control of seaweeds into the UK marketplace.

571 We appreciate the valuable and constructive comments of the anonymous reviewers

572 that have helped improve the clarity of our work.

\section{References}


574 Amon, P., Haas, E., Sumper, M., 1998. The sex-inducing pheromone and wounding 575 trigger the same set of genes in the multicellular green alga Volvox. Plant Cell 10, $576 \quad 781-789$.

577 Bikker, P., van Krimpen, M.M., van Wikselaar, P., Houweling-Tan, B., Scaccia, N., 578 van Hal, J.W., Huijgen, W.J.J., Cone, J.W., López-Contreras, A.M., 2016. 579 Biorefinery of the green seaweed Ulva lactuca to produce animal feed, chemicals $580 \quad$ and biofuels. J. Appl. Phycol. 28, 3511-3525.

581 Carl, C., de Nys, R., Lawton, R.J., Paul, N.A., 2014a. Methods for the induction of 582 reproduction in a tropical species of filamentous Ulva. PLoS One 9, e97396.

583 Carl, C., de Nys, R., Paul, N.A., 2014b. The seeding and cultivation of a tropical 584 species of filamentous Ulva for algal biomass production. PloS One, 9, e98700.

585 Corradi, M.G., Gorbi, G., Zanni, C., 2006. Hypoxia and sulphide influence gamete 586 production in Ulva sp. Aquat. Bot. 84, 144-150.

587 Dan, A., Hiraoka, M., Ohno, M., Critchley, A.T., 2002. Observations on the effect of 588 salinity and photon fluence rate on the induction of sporulation and rhizoid 589 formation in the green alga Enteromorpha prolifera (Müller) J. Agardh $590 \quad$ (Chlorophyta, Ulvales). Fish. Sci. 68, 1182-1188.

591 Föyn, B., 1959. Geschlechtskontrollierte Vererbung bei der marinen Grünalge Ulva mutabilis. Arch. Protistenk 104, 236-253. 
593 Gao, G., Clare, A.S., Rose, C., Caldwell, G.S., 2017. Eutrophication and 594 warming-driven green tides (Ulva rigida) are predicted to increase under future $595 \quad$ climate change scenarios. Mar. Pollut. Bull. 114, 439-447.

596 Gao, S., Chen, X., Yi, Q., Wang, G., Pan, G., Lin, A., Peng, G., 2010. A strategy for 597 the proliferation of Ulva prolifera, main causative species of green tides, with 598 formation of sporangia by fragmentation. PLoS One 5, e8571.

599 Goulitquer, S., Potin, P., Tonon, T., 2012. Mass spectrometry-based metabolomics to 600 elucidate functions in marine organisms and ecosystems. Mar. Drugs 10, $601 \quad 849-880$.

602 Gupta, V., Thakur, R.S., Baghel, R.S., Reddy, C.R.K., Jha, B., 2014. Seaweed 603 metabolomics: a new facet of functional genomics. Adv. Bot. Res. 71, 31-52.

604 Heinrich, S., Valentin, K., Frickenhaus, S., John U., Wiencke C., 2012. 605 Transcriptomic analysis of acclimation to temperature and light stress in 606 Saccharina latissima (Phaeophyceae). PLoS ONE, 7, e44342.

607 Hiraoka, M., Enomoto, S., 1998. The induction of reproductive cell formation of Ulva 608 pertusa Kjellman (Ulvales, Ulvophyceae). Phycol. Res. 46, 199-203.

609 Hiraoka M, Oka N., 2008. Tank cultivation of Ulva prolifera in deep seawater using a 610 new "germling cluster" method. J. Appl. Phycol. 20, 97-102.

611 Iken, K., 2012. Grazers on benthic seaweeds, in: Wienche C, B.K. (Ed.), Seaweed 612 Biology. Springer, Berlin, pp 157-175. 
613 Kalita, T.L., Titlyanov, E.A., 2011. The effect of temperature on infradian rhythms of 614 reproduction in Ulva fenestrata postels et ruprecht, 1840 (Chlorophyta: Ulvales). 615 Russ. J. Mar. Biol. 37, 52-61.

616 Kalita, T.L., Tytlianov, E.A., 2003. Effect of temperature and illumination on growth 617 and reproduction of the green alga Ulva fenestrata. Russ. J. Mar. Biol. 29, $618 \quad 316-322$.

619 Kapraun, D.F., 1970. Field and cultural studies of Ulva and Enteromorpha in the 620 vicinity of Port Aransas, Texas. Contrib. Mar. Sci 15, 205-285.

621 Kirkendale, L., Saunders, G.W., Winberg, P.A., 2013. A molecular survey of Ulva 622 (Chlorophyta) in temperate Australia reveals enhanced levels of 623 cosmopolitanism. J. Phycol. 49, 69-81.

624 Lehahn, Y., Ingle, K.N., Golberg, A. 2016. Global potential of offshore and shallow 625 waters macroalgal biorefineries to provide food, chemicals and energy: 626 Feasibility and sustainability. Algal Res. 17, 150-160.

627 Li, R., Brawley, S.H., 2004. Improved survival under heat stress in intertidal embryos 628 (Fucus spp.) simultaneously exposed to hypersalinity and the effect of parental 629 thermal history. Mar. Biol. 144, 205-213.

630 Liu, D., Keesing, J.K, Xing, Q., Shi, P., 2009. World's largest macroalgal bloom 631 caused by expansion of seaweed aquaculture in China. Mar. Pollut. Bull. 58, 632 888-895. 
633 Lüning, K., Kadel, P., Pang, S., 2008. Control of reproduction rhythmicity by 634 environmental and endogenous signals in Ulva pseudocurvata (Chlorophyta). J. 635 Phycol. 44, 866-873.

636 Masakiyo, Y., Shimada, S., 2014. Species diversity of the genus Ulva (Ulvophyceae, 637 Chlorophyta) in Japanese waters, with special reference to Ulva tepida Masakiyo 638 et S.Shimada sp. nov. Bull. Nat. Sci. Museum Ser. B. 40, 1-13.

639 Mohsen, A.F., Khaleata, A.F., Hashem, M.A., Metwalli, A., 1974. Effect of different 640 nitrogen sources on growth, reproduction, amino acid, fat and sugar contents in 641 Ulva fasciata Delile (Part III). Bot. Mar. 17, 218-222.

642 Niesenbaum, R.A., 1988. The ecology of sporulation by the macroalga Ulva lactuca 643 L.(Chlorophyceae). Aquat. Bot. 32, 155-166.

644 Nilsen, G., Nordby, Ø., 1975. A sporulation-inhibiting substance from vegetative 645 thalli of the green alga Ulva mutabilis, Føyn. Planta 125, 127-139.

646 Nordby, Ø., 1977. Optimal conditions for meiotic spore formation in Ulva mutabilis 647

648 Nordby, O., Hoxmark, R.C., 1972. Changes in cellular parameters during 649 synchronous meiosis in Ulva mutabilis Foyn. Exp. Cell Res. 75, 321-328.

650 Rautenberger, R., Bischof, K. 2006. Impact of temperature on UV-susceptibility of 651 two Ulva (Chlorophyta) species from Antarctic and Subantarctic regions. Polar 652 Biol. 29, 988-996. 
653 Shimada, S., Yokoyama, N., Arai, S., Hiraoka, M. 2008. Phylogeography of the genus 654 Ulva (Ulvophyceae, Chlorophyta), with special reference to the Japanese 655 freshwater and brackish taxa. J. Appl. Phycol. 20, 979-989.

656 Simpson, A.J., Mcnally, D.J., Simpson, M.J., 2011. NMR spectroscopy in 657 environmental research: from molecular interactions to global processes. Prog. 658 Nucl. Magn. Reson. Spectrosc. 58, 97-175.

659 Smetacek, V., Zingone, A., 2013. Green and golden seaweed tides on the rise. Nature $660 \quad 504,84-88$.

661 Smith, G.M., 1947. On the reproduction of some Pacific coast species of Ulva. Am. J. 662 Bot. $34,80-87$.

663 Stratmann, J., Paputsoglu, G., Oertel, W., 1996. Differentiation of Ulva mutabilis 664 (Chlorophyta) gametangia and gamete release are controlled by extracellular 665 inhibitors. J. Phycol. 32, 1009-1021.

666 Thiadens, A.J.H., Zeuthen, E., 1966. Meiosis and sporulation induced in sporophytes 667 of Ulva mutabilis (“slender”) with synchronous mitosis. Planta 72, 60-65.

668 Vesty, E.F., Kessler, R.W., Wichard, T., Coates, J.C., 2015. Regulation of 669 gametogenesis and zoosporogenesis in Ulva linza (Chlorophyta): comparison 670 with Ulva mutabilis and potential for laboratory culture. Front. Plant Sci. 6, 15. 671 doi: $10.3389 /$ fpls.2015.00015. 
672 Wichard, T., Oertel, W., 2010. Gametogenesis and gamete release of Ulva mutabilis 673 and Ulva lactuca (chlorophyta): regulatory effects and chemical characterization 674 of the "swarming inhibitor". J. Phycol. 46, 248-259.

675 Zhang, X., Ye, N., Liang, C., Mou, S., Xiao, F., Xu, J., Dong, X., Zhuang, Z., 2012. 676 De novo sequencing and analysis of the Ulva linza transcriptome to discover 677 putative mechanisms associated with its successful colonization of coastal 678 ecosystems. BMC Genomics 13, 1-13. 
680 Fig. 1. Light micrographs of Ulva rigida in the process of reproduction. (A)

681 vegetative cells, (B) reproductive cells before discharging gametes (red arrow), (C)

682 reproductive cells discharging gametes (blue arrow), and (D) discharged swarmers.

683 The scale bars represent $10 \mu \mathrm{m}$.

684 Fig. 2. The reproduction rates of Ulva rigida treated with increasing temperature 685 shock periods (in minutes). The reproduction rates were assessed three, four, and five 686 days post temperature shock treatment. Data are means \pm SD $(n=3)$ with each 687 replicate including 25 discs.

688 Fig. 3. Effects of two-step temperature shock on the reproduction rate of Ulva rigida.

689 The results were obtained on day five for the group of two hours. Zero represents 690 discs kept at $18{ }^{\circ} \mathrm{C}$ for two weeks without experiencing a temperature shock, and two 691 hours represents discs experiencing two hours of a $4{ }^{\circ} \mathrm{C}$ treatment before returning to $69218{ }^{\circ} \mathrm{C}$. One week, two weeks and three weeks indicate discs transferred from $18{ }^{\circ} \mathrm{C}$ to $6934{ }^{\circ} \mathrm{C}$ and kept at $4{ }^{\circ} \mathrm{C}$ for one week, two weeks, and three weeks respectively. Data 694 are means \pm SD $(n=3)$ with each replicate including 25 discs.

695 Fig. 4. The reproduction rates of Ulva rigida treated by increasing dehydration 696 periods (in minutes). The reproduction rates were assessed 10, 12, and 14 days post 697 dehydration treatment. Data are means \pm SD $(n=3)$ with each replicate including 25 698 discs. 
699 Fig. 5. Effects of tissue fragment size and media condition on the reproduction rates 700 of Ulva rigida on days five, six, and seven. Closed squares represent non-renewed 701 media treatment and open squares represent renewed media treatment. Data are means $702 \pm \mathrm{SD}(\mathrm{n}=3)$. Each replicate in the $2.5 \mathrm{~mm}$ diameter treatment includes 320 discs, 703 each replicate in the $4 \mathrm{~mm}$ diameter treatment includes 125 discs, each replicate in the $7046 \mathrm{~mm}$ diameter treatment includes 56 discs, each replicate in the $8 \mathrm{~mm}$ diameter 705 treatment includes 31 discs, and each replicate in the $10 \mathrm{~mm}$ diameter treatment 706 includes 20 discs.

707 Fig. 6. Combined effects of temperature shock, dehydration and fragmention on 708 reproduction of Ulva rigida on days two (A), three (B), and four (C). Small, Medium, 709 and Large are discs with diameters of 2.5, 4, and $6 \mathrm{~mm}$ respectively. FR, FR+DE, 710 FR+TS, and FR+TS+DE represent discs without temperature shock or dehydration 711 treatments, discs with a one hour dehydration treatment, discs with a six hour 712 temperature shock treatment, and discs with a six hour temperature shock and a one 713 hour dehydration treatment, respectively. Data are means $\pm \operatorname{SD}(n=3)$.

714 Fig. 7. Reproduction rates of blade and basal tissues of different ages observed seven 715 (A), 10 (B), and 14 (C) days after fragmentation and temperature shock treatments. 716 Data are the means \pm SD $(n=3)$.

717 Fig. 8. Inhibitory effects of basal tissues on the reproduction rates of blade tissues on 718 days 13,14 , and 15 . Data are means $\pm \operatorname{SD}(n=3)$. 
719 Fig. 9. Effects of temperature and nitrate on maturation of Ulva rigida. Data are

720 means $\pm \operatorname{SD}(\mathrm{n}=10)$.

721 

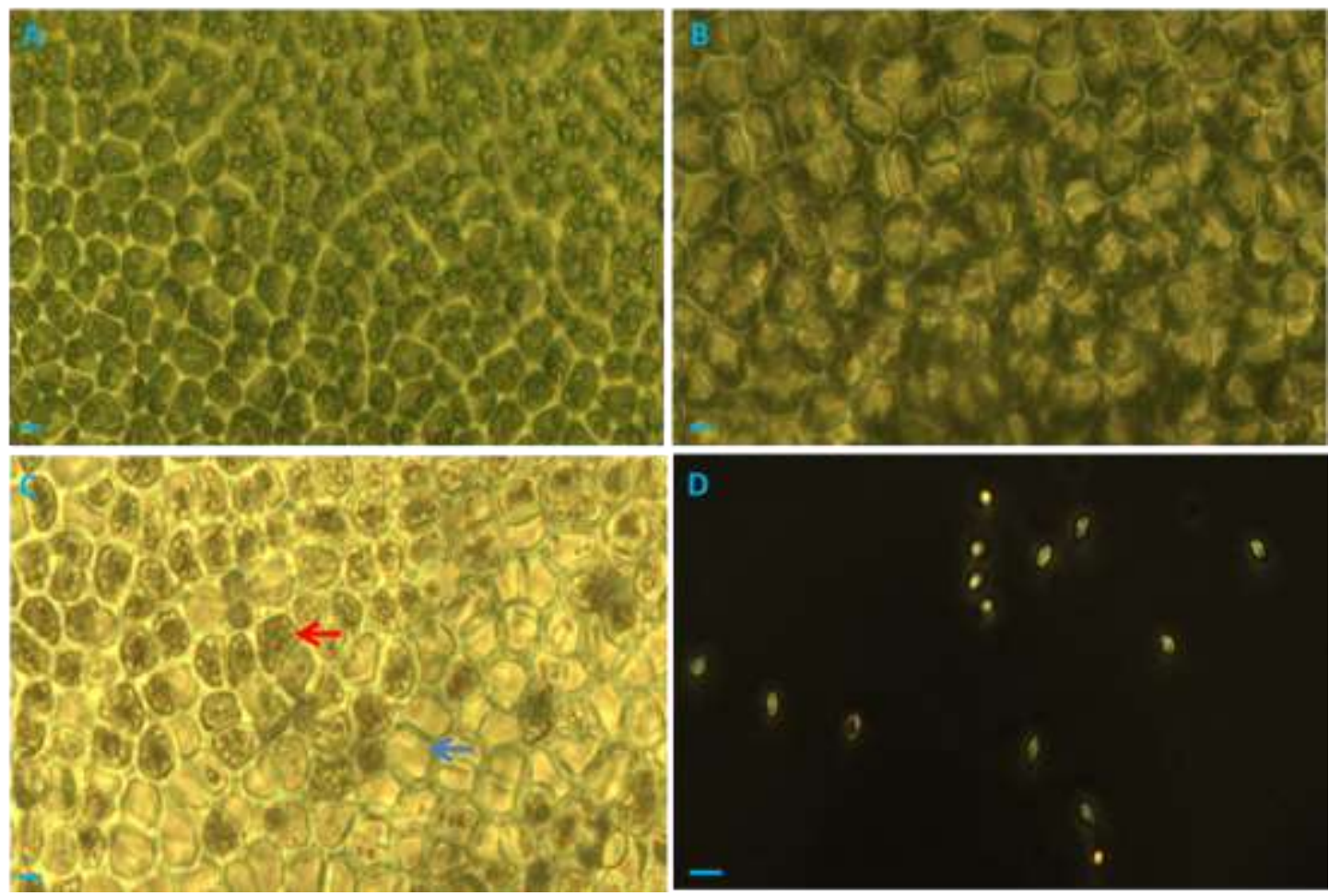

723

724 Fig. 1.

725 


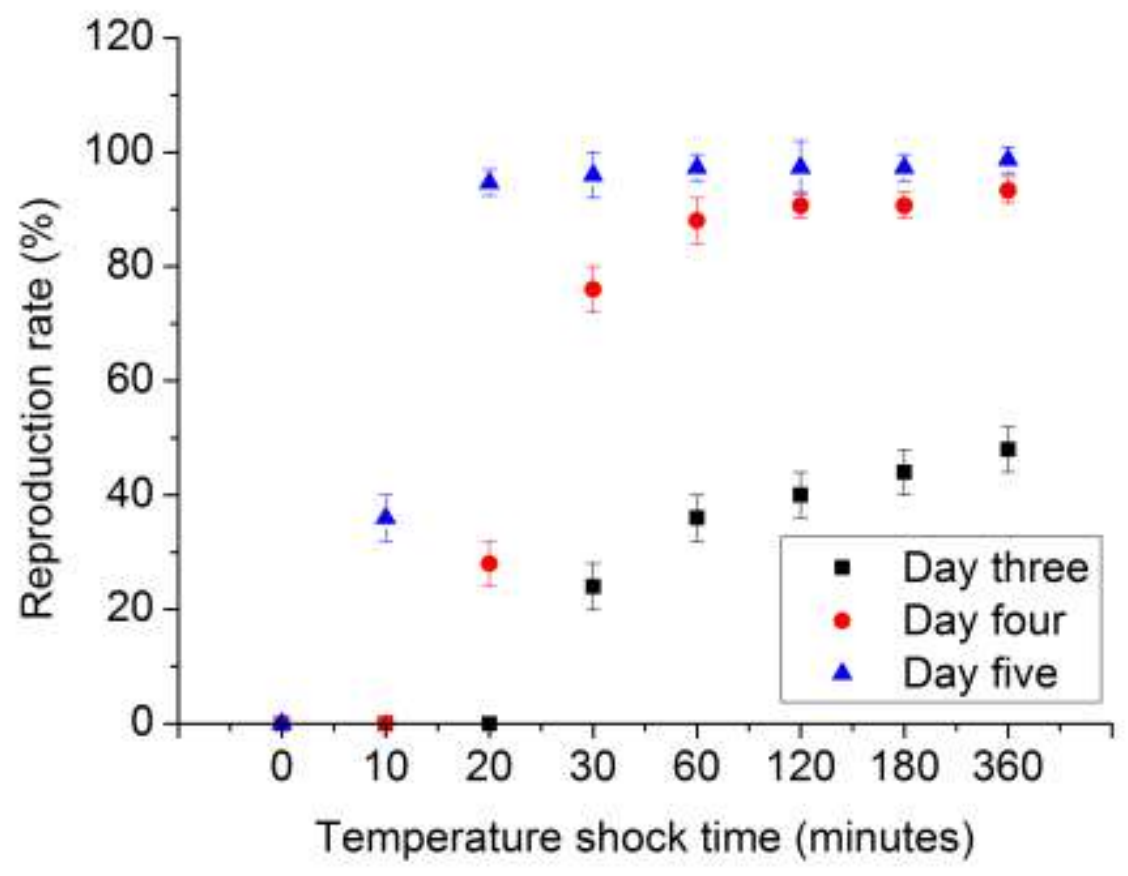

$728 \quad$ Fig. 2. 


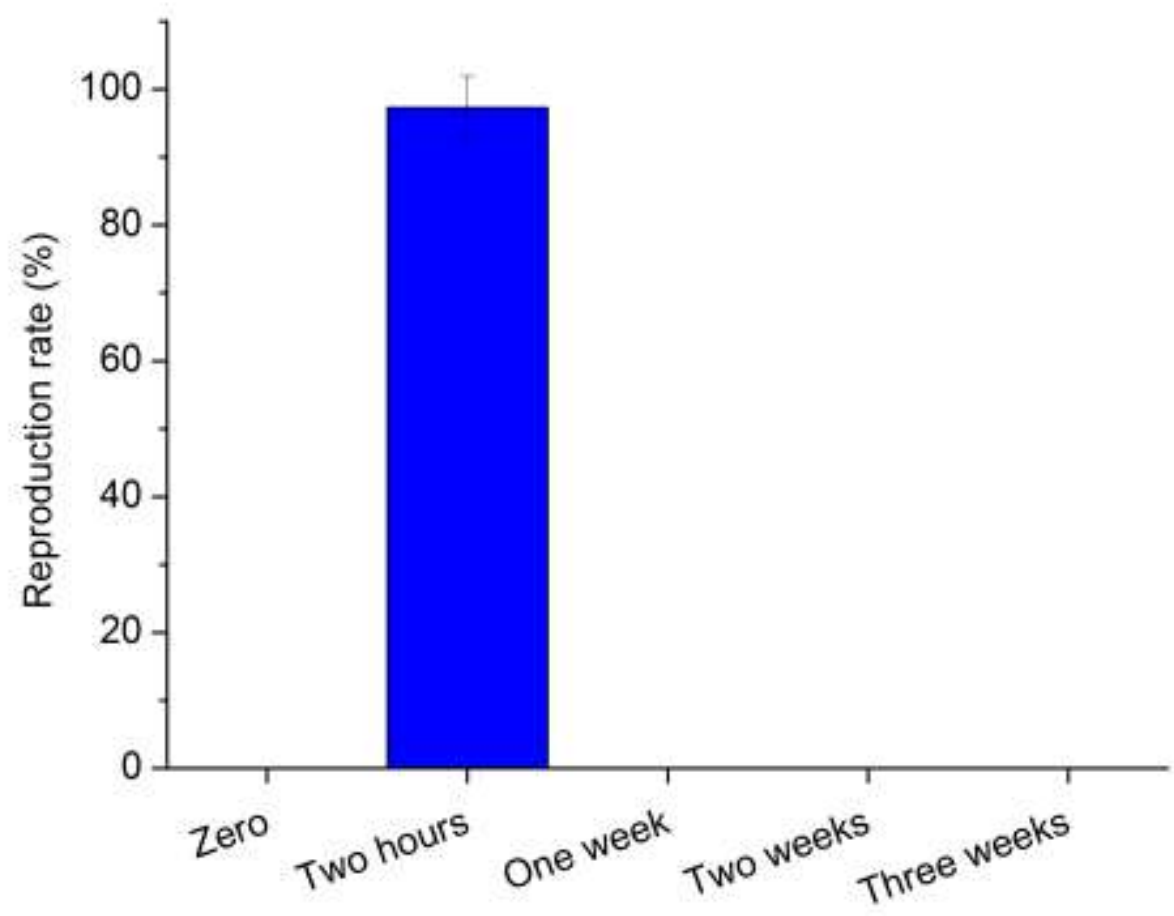

731

\section{Treatments}

$732 \quad$ Fig. 3.

733 


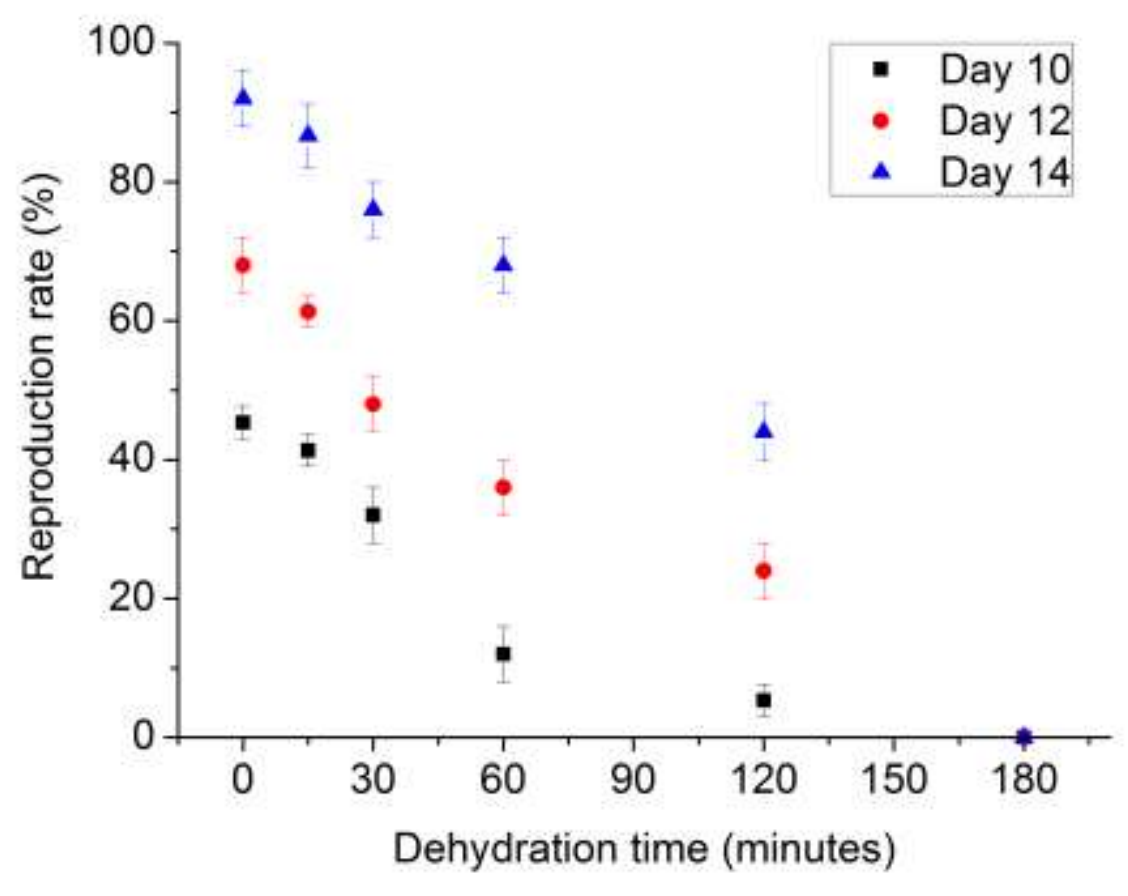

736

$737 \quad$ Fig. 4.

738 


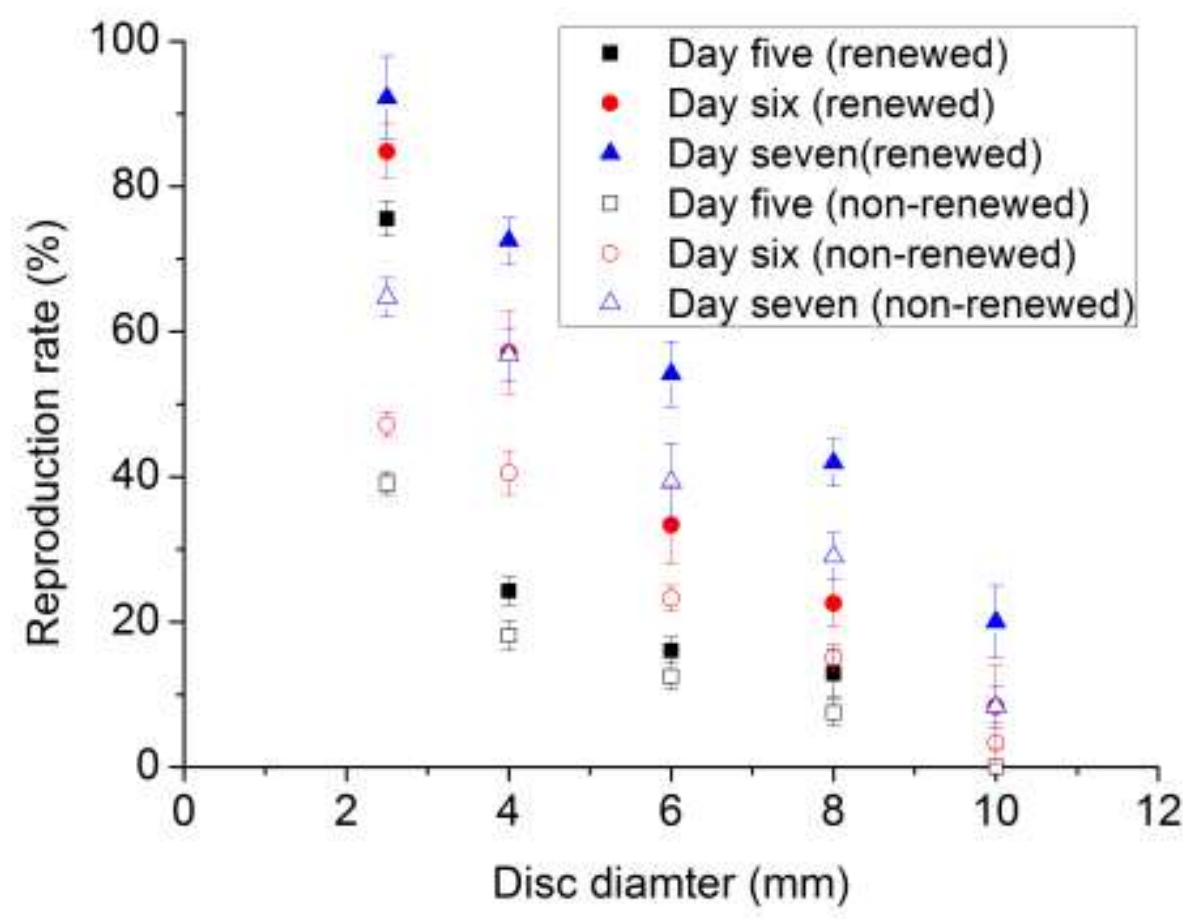

740

$741 \quad$ Fig. 5.

742 


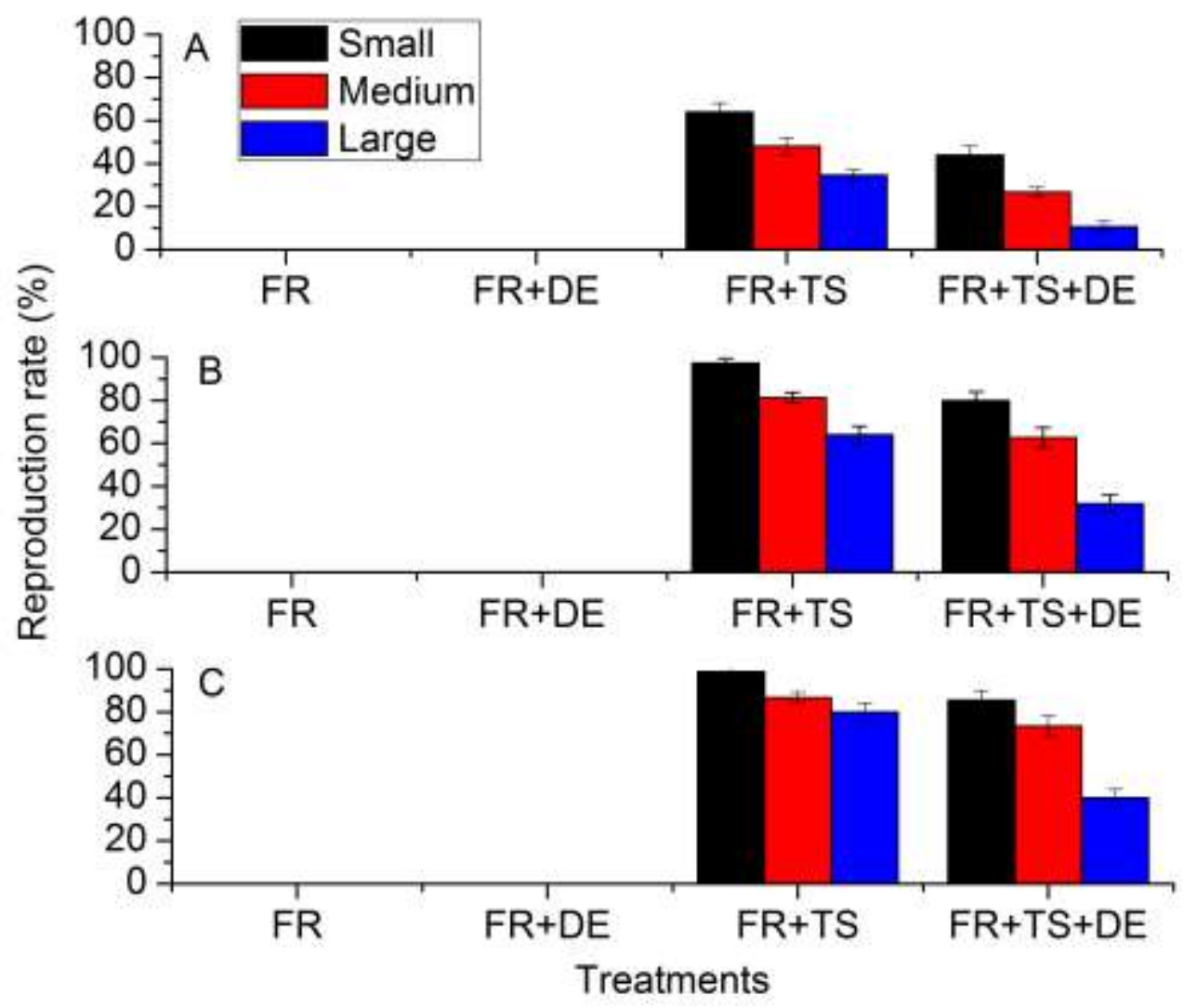

743

$744 \quad$ Fig. 6.

745 

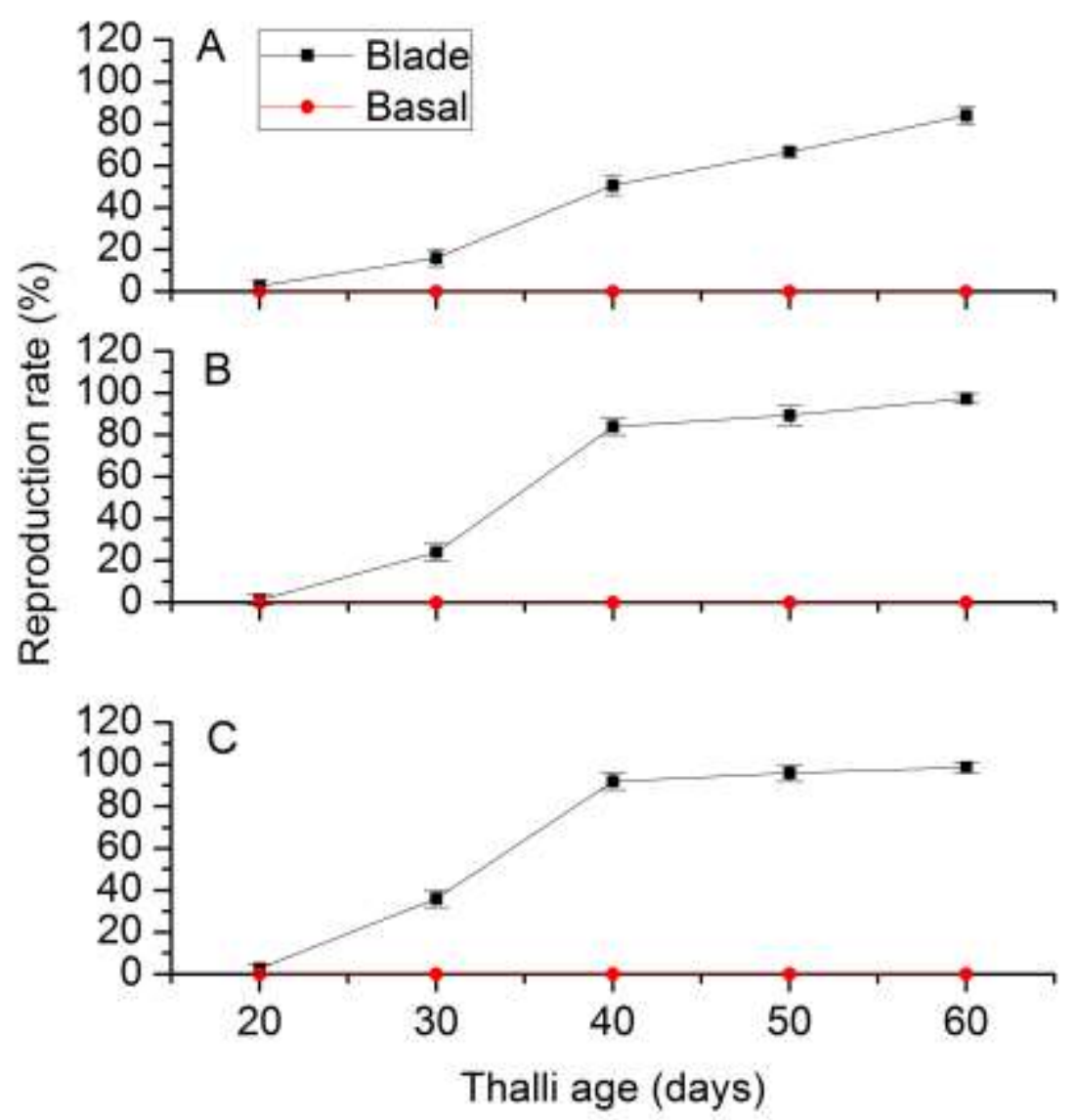

748

$749 \quad$ Fig. 7.

750 


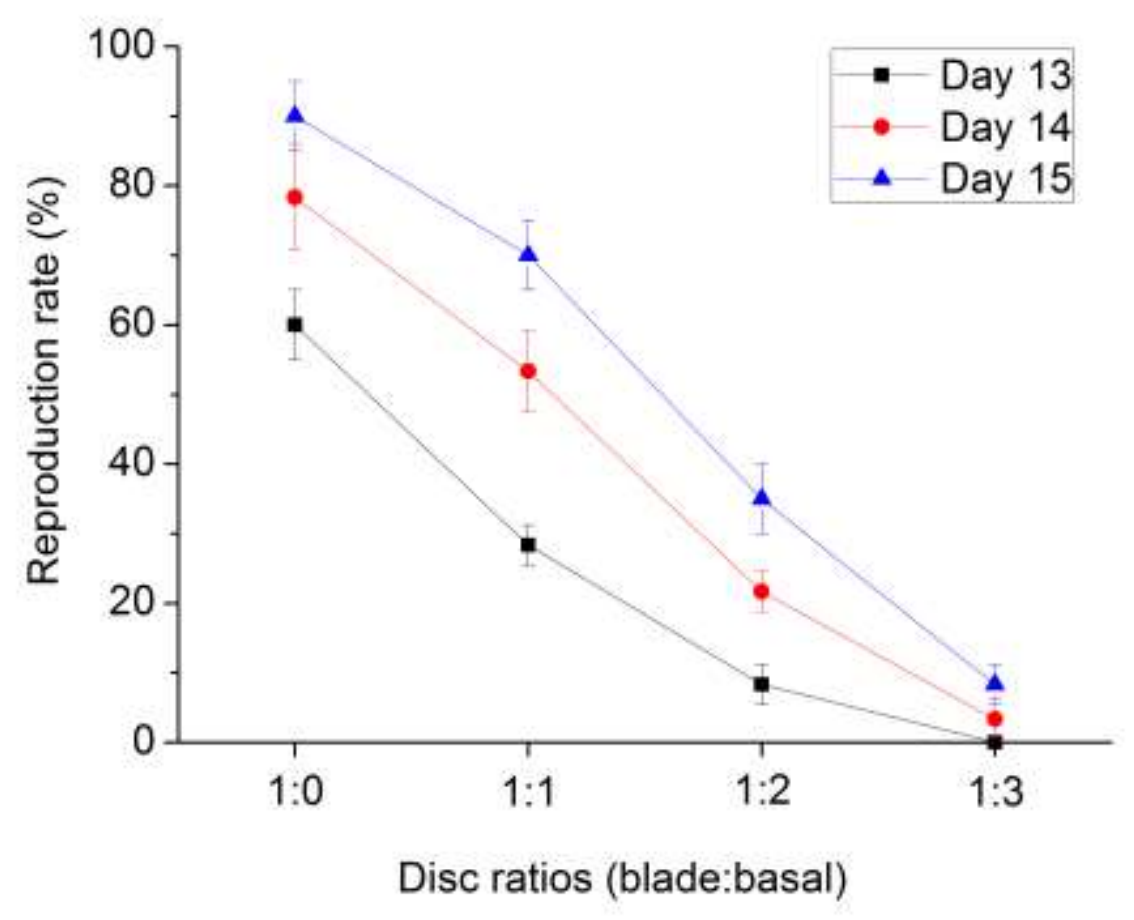

752

$753 \quad$ Fig. 8.

754

755 


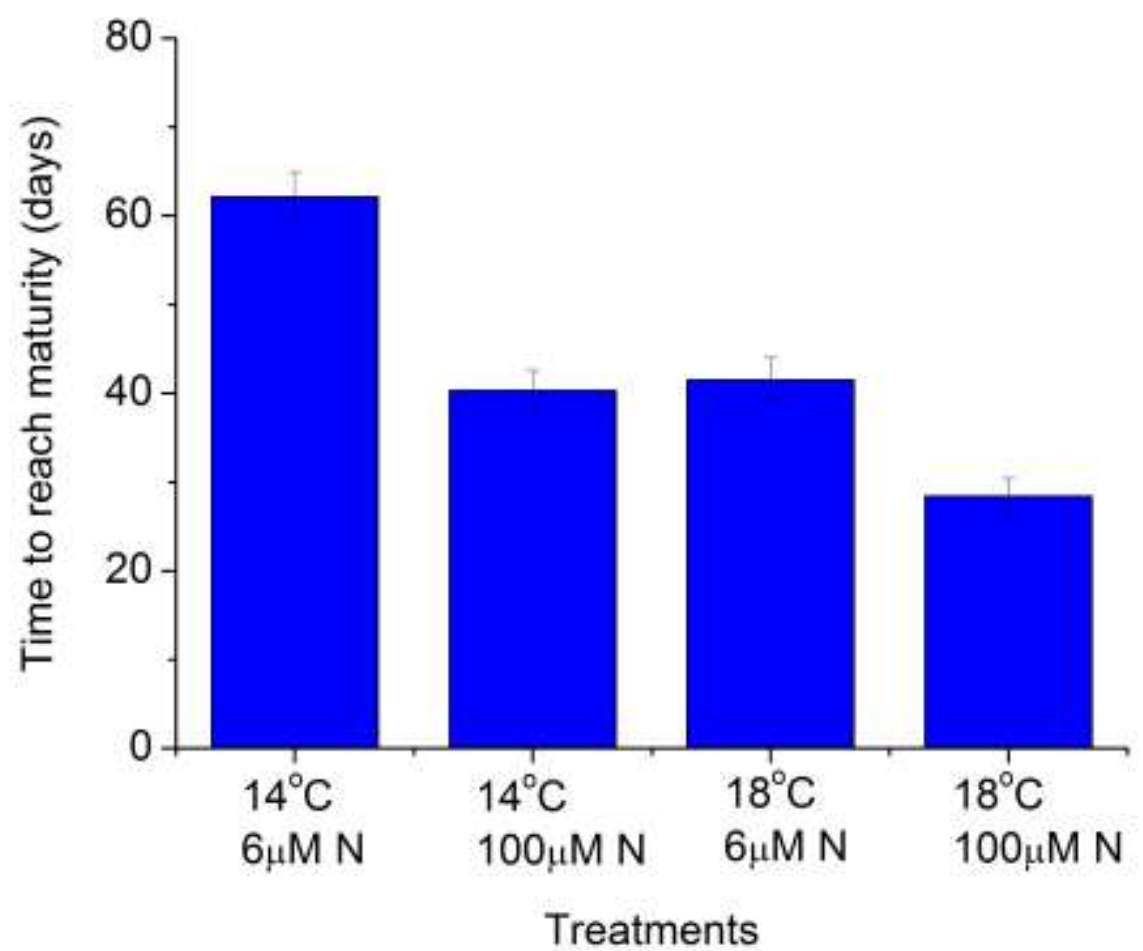

756

757 Fig. 9. 